\title{
An Exploration of Life Skills Programme on Pre-School Children in Embu West, Kenya
}

\author{
Jane Ciumwari Gatumu ${ }^{1, *} \&$ Wilfred Njeru Kathuri ${ }^{2}$ \\ ${ }^{1}$ School of Education, University of Nairobi, P.O. Box 30197- 00100, Nairobi, Kenya \\ ${ }^{2}$ Teacher Trainer, Embu County, Kenya \\ *Correspondence: School of Education, University of Nairobi, P.O. Box 30197- 00100, Nairobi, Kenya. Tel: \\ 254-722-599-724.E-mail: jgatumu@uonbi.ac.ke
}

Received: October 29, 2017

Accepted: November 7, 2017 Online Published: December 23, 2017

doi:10.5430/jct.v7n1p1

URL: https://doi.org/10.5430/jct.v7n1p1

\begin{abstract}
The Life Skills Programme, which is one of the newest programmes in the Kenya Preschool educational system was explored to establish the impact it had on the lives of preschool children in Embu West, Kenya. A primary school that is perceived as having well-disciplined children was purposively selected. The sample consisted of 39 students, 43 preschool teachers and 31 parents. The data collection methods included use of a questionnaire, interviews, observations and a documentary analysis. A content analysis was used to examine the data collected. A main finding was that, teachers and parents seemed to cherish the Life Skills Programme as a subject that enabled children to acquire relevant skills for their growth, development and survival. Another finding was an indication of a link between children who had mastered the life skills and academic performance. The study recommended the need to develop clear policy and supervisory guidelines to allow the effective implementation of the Life Skills Programme to benefit all children.
\end{abstract}

Keywords: life skills programme; preschool; primary school; competences

\section{Introduction}

A life skills programme endeavours to be a vehicle for the development of people in a multi-dimensional way. That is, the programme targets elements such as the cognitive, emotional and relational attributes of people. The anticipated outputs for the people who are enrolled in the programme are qualities such as self-esteem, sociability, tolerance, responsibility and freedom (Ferrari, Hogue \& Scheer 2004; Goody 2001; Ouane 2002). Therefore, the aim of such a programme is to provide people with tools for self-care, self-direction and survival in their society. A study by Albertyn, Kapp and Groenewald (2001) in South Africa has shown that following a life skills programme, the participants who consisted of 37 workers, were empowered. More specifically, the participants manifested positive qualities which included greater levels of feeling of confidence, critical thinking and a heightened feeling of autonomy. It would not be far-fetched to conclude that these attributes demonstrated by the workers positively contributed towards their work experiences.

In a Kenyan context, the Kenya Institute of Education (2008), defines life skills as competencies that a child acquires for effective adaptation and to be used to deal with the daily demands of life. Evidently, the Life Skills Programme goes beyond academic achievements. It is argued that the programme empowers children to manage new situations without getting discouraged and experiencing defeat (Kenya Institute of Education 2002; Mweru 2005). Children acquire skills, attitudes and values for development and survival in an environment that is ever changing (Goody 2001; Ouane 2002). It is proposed that the learning experiences that the children are exposed to due to the programme form a basis for their future undertakings in society.

At a logical level, the teachers who facilitate the programme have an important role. In addition, education scholars have argued that in curriculum implementation the teacher who organises learning experiences and manages the learning environment for the benefit of the children is key in determining the outputs (Alisinanoğlu, Özbey \& Kesicioğlu 2012; Gatumu 2010; Shiundu \& Omulando 1992). This may be the reason why Hawes (1979) argued that there is no conceivable way in which curriculum implementation can be divorced from the process of teacher education. 
Therefore, the influence that that teachers had was one of the focuses of this research.

In Embu West, which is a sub-county in Kenya, majority of preschool teachers are trained in preschool education either at certificate or diploma level. According to the District Education Office (2011) out of 153 teachers, 149 (97.4 percent) are trained while only 4 (2.6 percent) are not. Despite the fact that they had professional training, there was no evidence of training in the Life Skills Programme (District Education Office Embu West 2011). Given this shortcoming, the study intended to explore how the implementation of the Life Skills Programme prepared preschool children for next level of schooling and life. The findings are of potential use to stakeholders such as non-governmental organisations, and the tertiary education sector for advocacy and policy advancement on the importance of the Life Skills Programme among the children and youth. This would then form a basis for strengthening and motivating teachers and parents to support the programme's implementation in a more systematic manner.

The Ecological System Theory (Bronfenbrenner 1989) formed the basis of this exploration. The theory demonstrates that the being of a child is a result of micro, meso and macro systems. The preschool setting, an output of these three systems, was viewed to be essential in contributing towards preparing the child for a self-fulfilled life through Life Skills Programme. Thus, the purpose of the research was to explore the effects of the Life Skills Programme on children who are at a point of their school lives where they are transitioning from preschool to primary school. The focus was on the skills children display as they interact with their new social and physical environments in primary school.

\section{Method}

A case study research design was used to address the research aim. The case study design enabled the collection of in-depth data on the exploration of the Life Skills programme. The researchers purposively selected one public primary school in Embu West Sub-County that is perceived in the community as having a high level of discipline. The sample consisted of 39 children who were in primary one (they were in preschool the year preceding data collection) and 31 of their parents. In addition, using stratified random sampling technique, 43 preschool teachers from the Sub-County were selected to participate in the study. The 43 preschool teachers were randomly selected from the 57 public preschools and 71 private preschools.

The data collection procedures were as follows:

1. The 43 preschool teachers were subjected to an open-ended questionnaire where they freely expressed the key competencies connected to Life Skills Programme which preschool children should acquire by the time they move on to primary school. The open-ended questionnaire was used due to its advantages in that it permits greater depth of responses.

2. An interview schedule was used to gather data from the 31 parents on changes they had seen in their children's behaviour and attitude to life which could be attributed to Life Skills Programme. This data collection procedure is similar to Ferrari, Hogue and Scheer (2004) who used interviewing to obtain parent's perspectives on a life skills programme.

3. An observation schedule was used to record the competencies the primary one primary school children had acquired from the Life Skills Programme that was provided at their preschool. The observations were made during the first two weeks of the first term as the children moved from preschool to primary one. The direct observations enabled the researchers to identify children's behaviours and attitudes as they adjusted to different classroom contexts (Lee 2006).

4. The Life Skills Programme syllabus' objectives and content were accessed through use of documentary analysis schedule. The data obtained using this procedure served as a way to corroborate data that was collected using the other procedures (Miles \& Huberman 1994).

The data collected was mainly qualitative in nature. Content analysis of the competencies from the questionnaires, observations, interview schedules and documentary analysis schedule paved the way for calculation of frequencies and percentages. Then, combining both the qualitative and quantitative techniques, a description of competencies children displayed in their daily interactions in school and home was made.

\section{Results and Discussion}

The documentary analysis of the Kenya Institute of Education Life Skills Programme syllabus identified the competencies that children who were moving from preschool to primary one in primary school, were expected to have 
acquired. The identified competencies were: awareness of self, being assertive, effective communicating with others and observance of personal hygiene (Kenya Institute of Education 2008). These themes that emerged from the syllabus agree with what the preschool teachers indicated in their questionnaire responses as their expectations for their preschool children. The competencies capture the skills that children need as they grow, develop and thrive to fit in the physical and social environments of their lives. Malti and Latzko (2010) highlight that the purpose of a life skills programme is to empower children to fit in various contexts of the society's life. Thus, the output of the programme is that preschool children become functional in the life of the society.

Table 4.1 below shows that feeding self was the most cited competency (that is by 35 (81.4\%) preschool teachers). Feeding self is a self-help skill (Zigler \& Stevenson 1993). This is a skill that touches on children's physical development in that they can generally coordinate their fine hand muscles subsequent to sufficient practice (Venetsanou, Kambas, Ellinoudis, Fatouros, Giannakidou \& Kourtessis 2011). In a study on effect of age and gender on 283 children's balance skills in Peloponnesus, Southern Greece, the researchers found that age may be a significant factor in children's balancing skills while gender did not feature as a significant factor (Venetsanou et al. 2011). Feeding self is an independence and responsibility oriented competency as it demands a child to take charge of his or her feeding situation at hand, display maturity and autonomy and ability to balance physically.

Table 1. Pre-School Teachers' Life Skills Competences for Preschool Children

\begin{tabular}{lcc}
\hline Skill & Frequency & Percentage \\
\hline Feeding self & 35 & 81.40 \\
Dressing & 30 & 69.77 \\
Personal hygiene & 30 & 69.77 \\
Self-awareness & 34 & 79.10 \\
Safety & 20 & 46.51 \\
Relating well with others & 20 & 46.51 \\
\hline
\end{tabular}

$\mathrm{N}=\mathbf{4 3}$

Table 2 below shows the skills that the children displayed as they were observed in their school activities. From the researchers' observations, it was recorded that $34(87.2 \%)$ children had acquired self-feeding competence while five $(12.8 \%)$ had not. These 34 children seemed excited that they were capable of feeding themselves and would finish their food faster than the five who were either being fed or under strict supervision by the teacher. From the 34 children mobility ability and self-satisfaction were noted in that they would display their empty plates to the teacher to show that the eating exercise was over and needed to be congratulated for a job well done. The ability to feed self, enabled them to immediately engage in other physical social activities like peer playing while the five slow ones seemed victims restrained for movement until they finished, experiences many times they never participated in.

Table 2. Life Skills as Primary School Children Were Observed

\begin{tabular}{lccccc}
\hline Skills & \multicolumn{3}{c}{ Acquired } & \multicolumn{2}{c}{ Not acquired } \\
\cline { 2 - 5 } & F & $\%$ & F & $\%$ \\
\hline Self-awareness & 36 & 92.0 & 3 & 33.3 \\
Effective communication & 25 & 64.7 & 14 & 35.3 \\
Personal hygiene & 36 & 91.2 & 3 & 8.8 \\
Feeding self & 34 & 87.2 & 5 & 12.8 \\
Dressing & 36 & 91.2 & 3 & 8.8 \\
Safety & 30 & 76.5 & 9 & 23.5 \\
Relating to strangers & 0 & 76.5 & 9 & 23.5 \\
\hline
\end{tabular}

$\mathbf{N}=\mathbf{3 9}$

Of concern are the five children who had not acquired this skill. They could not hold their plates and spoons steadily and looked rather untidy as they poured food on themselves. These five children needed strict supervision from the teacher as they ate. They were slow and took much of the teachers' time. It is important to note that these same children were rather under-achievers academically making them be children at risk and demanding a special programme to 
enable them to enjoy their being in school for broader interesting physical and social tasks. It also shows how life skills influence other dimensions of a child's life (Shala 2009). Shala's study in Kosovo on social emotional skills and children's academic performance showed that children's level of social emotional skills was a significant predictive factor in relation to how they performed academically.

Children dressing themselves was another competency that demanded coordination of motor skills. As shown in Table 1, it was $30(69.77 \%)$ teachers who presented it as an essential competency that shows that a child has matured. An example of a way in which this competency was demonstrated was the way the children dressed themselves after a PE lesson (Lee 2006). In the interviews, one parent expressed it as an important competency because it saves her time in the morning which tended to be extremely hectic. The observations also showed that the children who could feed themselves, could dress themselves; they kept themselves clean and even wanted teachers to note that they were neatly dressed (Zigler \& Stevenson 1993). There were $36(91.2 \%)$ children who could dress and display their individuality as they interacted with the immediate environment, while three $(8.8 \%)$ children could not. Many of those who had mastered the skill had passion as they did it. This is showing one's independence as suggested by Eggen and Kauchak (2012). For instance, the primary school teacher of the 39 children commented that dressing was a moment for a child to show off, getting excited and deliberately showing high self-esteem.

Observing personal hygiene was another widely cited competency (that is by $30(69.77 \%)$ teachers). At a preschool level, children are vulnerable to infections which can be avoided (Zigler \& Stevenson 1993). Observing hygiene is also a practical competency expected from children. Through this skill of observing hygiene, a child is seen to be in control of what he/she does. It is a competency by which a child manages and controls his/her environment for health reasons (Meggitt \& Walker 2004). According to the observations, 36 (91.2\%) children had acquired a competency in personal hygiene, showing that they could protect themselves from basic forms of infection. This competency was demonstrated by washing of hands, proper use of the toilets and keeping oneself presentable. It was also observed that the 36 children tended to relate well with others; could communicate effectively with others and when it came to feeding themselves, they managed without much problem. One child was heard telling the others that one can get sick if one does not wash hands before eating. The same child made a connected comment in class when the teacher announced that one of the children was absent and the child said that it is because she had not washed her hands before eating the previous day. This attitude of exhibited by the child reinforces the notion that children have a role to play in promoting health messages to others (Hawes \& Scotchmer 1993).

A contradiction can be noted between parents' and teachers' responses on personal hygiene. Most teachers, 30 $(69.77 \%)$ mentioned personal hygiene, while only one (3.3\%) parent mentioned it in the interviews. The disparity may be due to fact that home and school environments are different. In a home environment, children tend to receive a lot of attention from their parents/guardians like being frequently washed and changed unlike in school where children spend much time playing with their peers in all manner of scenarios. More so, the teacher lets children move freely as they interact with other immediate environments. Also, the diverse backgrounds of the children may tend to influence the teacher in putting much emphasis on the importance of observing hygiene as they interact with each other (Hawes \& Scotchmer 1993).

Relating well with others was cited by 20 (46\%) teachers, while 30 children displayed this competency during the observations. Logically, this is an important skill to facilitate children's adjustment to new school settings. According to Katz and McClellan (1997) the ability of children to interact with other people leads children to maximise their potential. The skill of relating well with others can be quantitatively measured and evaluated through children's social dynamics like play (Lee, 2006). Children's status of the ability to relate well with others was observed as they undertook group tasks. On one observed incident, as the teacher grouped the children in a Social Studies lesson to model a family member, one child chose to work alone. This child on his own modelled a father holding a slasher. His attitude towards others emerged when he volunteered to talk about his model to other children. With a lot of gratification, he shared with others that he had modelled his father who had used a slasher to chase away thieves from their house. The teacher and other children applauded him for displaying a protective attribute and for being aware of his fellow classmates. Mweru (2005) presents this picture of children sharing with their peers as very self-fulfilling in her analysis of sibling teaching among the Agikuyu of Kenya. In an earlier study of children in Embu, Kenya, Njenga and Kabiru (2001) highlighted the group personality oriented life skills, which a child needs to grow holistically in a dynamically changing Kenya society. Njenga and Kabiru (2001) emphasise on the role of the school and the family in enhancing social relationship skills. Similarly, Alisinanoğlu, Özbey and Kesicioğlu (2012) in research to show the relationship between social skills and children's behaviour problem in Gazi, Turkey, showed that both the family and school should cooperate to reduce children's behaviour problems. In fact, children working with one another and their parents is the philosophy advocated by Reggio Emilia approach to maximise children's construction of knowledge, 
skills and values (Rinaldi 2006).

Most of the teachers, that is, $34(79 \%))$ indicated that they expected all the children to have the skill of self-awareness. From the observations, $36(92 \%)$ of the children observed, had acquired self-awareness as a competency while $3(8 \%)$ had not. The 36 children could state their personal details which included, their name, parental names; where they lived; name of their preschool and their primary school. Basically, they knew who they were. The other 3 children who could not express themselves clearly and were not aware of who they were raises a concern as one wonders what was happening in the classroom. It was observed that these three children were rather withdrawn and the teacher did not seem to integrate them to the community life in the class so that they could engage in activities of others. During the observation, one six-year-old boy could not even express his parents' names and where they lived. When asked whether he was a boy or girl, he could not distinguish the two. This child seemed to be at risk in handling environmental issues and thus may require a special attention programme to help him be and become. Katz and McClellan (1997) and Smidt (2007) recommend that setting a stimulating environment is vital for children to be communities and to be individuals. The observed class was too big for a single teacher teaching all the subjects to these 39 children.

Observing personal safety and relating to strangers as competencies had each been acquired by $30(76 \%)$ children and not acquired by nine (23.5\%). Competencies on safety and relating to strangers are crucial in relation to responding to the environment by making a rational judgement. This is a skill which highly depends on how the child is socialised at home (Njenga \& Kabiru 2001; Bronfenbrenner 1989). There were children who would rush to strangers as if they knew them and this is deemed risky. Those strangers the teacher welcomed warmly into the class found themselves accepted by most of the children. During play in the field, the nine children would move aimlessly even to grounds not marked for play by the teacher. The teacher gave an incident of a child who got badly hurt by thorns and stones as he wandered from others to show mastery of the environment. Surprisingly this child wandered while other children still called on him and reported it to the teacher.

The findings on the identified competencies acquired by these children in primary one support the assertion by Nutbrown (2006) that children replicate what they have mastered and acquired in their earlier learnings. Therefore, the learned experiences in the Life Skills Programme at preschool are important in their transition to primary one and subsequent life. This suggests that the benefits that accrue to children because of being taught Life Skills Programme far outweigh any challenges that may be experienced (Shala 2009). For the Life Skill Programme to be productive and have a positive impact on the users, the programme must be anchored on a perspective that emphasises the mutual and dynamic interaction between individuals and society (Edelstein 2010). An environment for free movement and expression may be a necessary condition needed for enhancing maximum growth and development of autonomy such that the children become responsible, independent and altruistic adults (Eggen \& Kauchak 2012; Rinaldi 2006).

\section{Conclusion and Recommendations}

The competencies addressed by the Life Skills Programme are important for children as they transition from preschool to primary one. An inference that can be made from the findings is that life skills at preschool level can form a basis of predicting how well children perform in future life and later schooling. The competencies are characteristics of a self-fulfilled life for a mature person. Thus, teaching preschool children Life Skills Programme paves the way for their schooling and social responsibilities. In this regard, how the programme is implemented becomes central for its future benefits to children's lives.

It is recommended that the Ministry of Education, Science and Technology in Kenya develops more policy and supervisory guidelines to allow Life Skills Programme more effective implementation targeting all children. A more integrated approach framework to teach the Life Skills Programme could be formulated to ensure that all preschool activity areas contribute towards the attainment of healthy and productive lives for all children.

\section{References}

Albertyn, RM., Kapp, CA., \& Groenewald, CJ. (2001). 'Patterns of empowerment in individuals through the course of a life-skills programme in South Africa', Studies in the Education of Adults, 33(2), 180-200. https://doi.org/10.1080/02660830.2001.11661453

Alisinanoğlu, F., Özbey, S., \& Kesicioğlu, OS. (2012). Impact of social skill and problem behavior training program on children attending preschool: a survey. Academic Researh International, 2(2), 321-330.

Bronfenbrenner, U. (1989). Ecological Systems Theory. Annals of Child Development, 6, 187-24. 
District Education Office Embu West (2011). Preschool teachers record, unpublished.

Edelstein, S. (2010). Life cycle nutrition: an evidence-based approach. Jones \& Bartlett Publishers, Burlington.

Eggen, P., \& Kauchak, D. (2012). Strategies and models for teachers: Teaching content and thinking skills (6th ed.). Pearson, Boston.

Ferrari, TM., Hogue, CA., \& Scheer, SD. (2004). Parents' perceptions of life skills development in the 4-H cloverbud program. Journal of Extension, 42(3).

Gatumu, JC. (2010). Head teachers' tasks in the implementation of preschool curriculum in Kenya public preschools. IFE PsychologIA: An International Journal, 18(1), 11-26. https://doi.org/10.4314/ifep.v18i1.51649

Goody, J. (2001). Competencies and education: Contextual diversity. Defining and selecting key competencies, pp. 175-190.

Hawes, H., \& Scotchmer, C. (1993). Children for Health. ERIC.

Hawes, HWR. (1979). Curriculum and reality in African primary schools. Longman Publishing Group.

Katz, LG., \& McClellan, DE. (1997). Fostering Children's Social Competence: The Teacher's Role. Volume 8 of the NAEYC Research into Practice Series. ERIC.

Kenya Institute of Education (2002). Life Skills Education for Youth. Kenya Institute of Education, Nairobi.

Kenya Institute of Education (2008). Early Childhood Development and Education Syllabus. Kenya Institute of Education, Nairobi.

Lee, E-Y. (2006). 'Measuring social competence in preschool-aged children through the examination of play behaviors', Ed.S thesis, University of South Florida.

Malti, T., \& Latzko, B. (2010). Children's moral emotions and moral cognition: Towards an integrative perspective. New Directions for Child and Adolescent Development, 2010(129), 1-10. https://doi.org/10.1002/cd.272

Meggitt, C., \& Walker, J. (2004). An introduction to child care and education. Hodder \& Stoughton, London.

Miles, MB., \& Huberman, AM. (1994). Qualitative data analysis: An expanded sourcebook. SAGE, Thousand Oaks.

Mweru, M. (2005). Sibling teaching among the Agikuyu of Kenya. Tectum-Verlag.

Njenga, A., \& Kabiru, M. (2001). In the Web of Cultural Transition: A Tracer Study of Children in Embu District, Kenya. Early Childhood Development: Practice and Reflections. Following Footsteps, ERIC.

Nutbrown, C. (2006). Threads of thinking: Young children learning and the role of early education. SAGE, Thousand Oaks.

Ouane, A. (2002). Key competencies for lifelong learning. Institutionalising Lifelong Learning: Creating Conducive Environments for Adult Learning in the Asian Context, ed. by Madhu Singh, pp. 311-325.

Rinaldi, C. (2006). In dialogue with Reggio Emilia: Listening, researching and learning. Routledge, London. https://doi.org/10.4324/9780203317730

Shala, M. (2009). Assessing gross motor skills of Kosovar preschool children. Early Child Development and Care, 179(7), 969-976. https://doi.org/10.1080/03004430701667452

Shiundu, JS., \& Omulando, SJ. (1992). Curriculum: Theory and practice in Kenya. Oxford University Press, Nairobi.

Smidt, S. (2007). A guide to early years practice. Routledge, London.

Venetsanou, F., Kambas, A., Ellinoudis, T., Fatouros, I., Giannakidou, D., \& Kourtessis, T. (2011). Can the Movement Assessment Battery for Children-Test be the "gold standard" for the motor assessment of children with Developmental Coordination Disorder? Research in developmental disabilities, 32(1), 1-10. https://doi.org/10.1016/j.ridd.2010.09.006

Zigler, EF., \& Stevenson, MF. (1993). Children in a changing world: Development and social issues. Thomson Brooks/Cole Publishing Co, Pacific Grove. 